\title{
Der \\ Einfluss von Jod, Jodnatrium und Jodothyrin auf den Blutkreislauf.
}

Von

Dr. A. Gr. Barbèra aus Bologna.

Unter obigem Titel ${ }^{1}$ ) hat Dr. Laudenbach eine längere Untersuchung veröffentlicht, die es bezweckt, die Schlussfolgerungen, welche in meiner in diesem Archiv (Bd. 68) erschienenen Arbeit über die Erregbarkeit der Herz- und Gefässnerven nach Injection von Jod, sowohl wie die ersten Mittheilungen von E. v. Cyon über die Wirkungen des Jodothyrins zu widerlegen. Was den letzteren Theil der Laudenbach'schen Untersuchung anbetrifft, so muss es v. Cy on überlassen werden, wenn er es für nothwendig erachten sollte, auf dieselbe einzugehen. Dies erscheint mir auch kaum erforderlich: v. Cy on arbeitete mit Jodothyrin von Baumann; seine Angaben beziehen sich nur auf dieses Präparat. Laudenbach dagegen hat mit einem Jodothyrin von Notk in gearbeitet, dessen Herstellungsweise und Wirkungen uns unbekannt sind.

So viel man die letzteren nach den Angaben von Laudenbach beurtheilen kann, ist das Notkin'sche Jodothyrin schon in relativ kleinen Dosen absolut tödtlich; es erhält sich in alkalischer Lösung nur ganz kurze Zeit, kaum einige Stunden. Das Baumann'sche Jodothyrin in ebensolcher Lösung hat v. Cyon viele Monate unverändert erhalten, wie die Versuche zeigen, wo 1 oder $2 \mathrm{ccm}$ einer solchen Jodothyrinlösung noch im Stande waren, die lähmende Wirkung des Atropin auf die Vagi aufzubeben.

Auf's Herz- und Gefässsystem wirkt dieses Jodothyrin auch in minimalen Dosen und gerade in entgegengesetztem Sinne als das Notkin'sche Präparat.

Es ist schade, dass Dr. Laudenbach die so leieht auszuführende Probe der antagonistischen Wirkungen von dem Atropin

1) Kief 1898. Universitätsbuchdruckerei (russisch). 
und Jodothyrin nicht nachgemacht hat; er würde sich dann wahrscheinlich noch leichter überzeugt haben, dass es sich um zwei ganz verschiedene Präparate handelt. Boruttau hat neuestens die Angaben von $\mathrm{Cy}$ on über die antagonistischen Wirkungen von Jodothyrin und Atropin vollauf bestätigt. (Dieses Archiv Bd. 78 S. 127.)

Welche dieser beiden Präparate mehr der physiologischen Bestimmung des Jodothyrins näher kommt, ist leicht zu entscheiden ${ }^{1}$ ): Sämmtliche Forscher, welche mit Schilddrüsenextracten oder mit Jodothyrin gearbeitet haben, stimmen darin überein, dass dieselben den Blutdruck herabsetzen und die Pulsschläge verlangsamen.

In gleichem Sinne wirken nach v. Cy on auch Injectionen des Baumann'schen Präparates.

Das Notkin'sche Präparat dagegen erhöht den Blutdruck und beschleunigt die Pulsschläge.

Freilich führt auch Dr. Laude $\mathrm{nbach}$ einen einzigen Versuch an (XVI), wo er das von der Bayer'sehen Fabrik bezogene Jodothyrin verwendet hat. Er selbst nimmt aber an, dass hier das Jodothyrin zersetzt war. Auch v. Cy o n hat über solehe Fälle berichtet, wo das zersetzte Jodothyrin drucksteigernde Wirkungen erzeugt hat ${ }^{2}$ ).

Wahrscheinlich hat man es bei dem Präparat von Notkin mit den Producten zu thun, deren toxische Wirkungen in der Schilddrüse dureh Bildung des Jodothyrins unschädlich gemacht werden sollen ${ }^{3}$ ).

Die Versuche Dr. Laudenbach's mit Jod- und Jodnatriumeinspritzungen beziehen sich direct auf meine Untersuchung. Auf dieselben soll hier näher eingegangen werden.

Nach den allgemeinen Sahlussfolgerungen Dr. Lauden bach's scheinen die Ergebnisse dieser Versuche in grellem Widerspruche mit den meinigen $\mathrm{zu}$ stehen. Seiner Ansicht nach soll ich reine Wirkungen von Natrium dem Jod zugeschrieben haben. In der That habe ich bei meinen Versuchen meistens das Jod in der Form von Jodnatrium eingeführt. Ein Widerspruch zwischen unseren Schlüssen hätte sich also auf diese Weise erklären lassen, wenn die Versuche, welche Dr. Laudenbach mit Einführungen von Jod

1) Wir wollen schon von den glanzenden therapeutischen Erfolgen des Baumann'schen Jodothyrins bei Erkrankungen der Schilddrüse ganz absehen.

2) Physiologische Herzgifte. IV. Theil. Dieses Archiv Bd. 74 S. 274.

3) Physiologische Herzgifte. I. Theil. Dieses Archiv Bd. 73 S. 43. 
gemacht hatte, den meinigen auch wirklich entgegengesetzte Resultate geliefert hätten. Es genügt aber, seine Versuchsangaben nur etwas genauer nachzusehen, um die Ueberzeugung zu gewinnen, dass sie in der Wirklichkeit in vollster Uebereinstimmung mit den meinigen sind, trotzdem in denselben häufig nur reines Jod eingeführt wurde. Sie bestätigen also in der möglichst erwünschten Weise meine Angaben.

Aus meinen Untersuchungen sowie aus denen von v. Cyon schlossen. wir, dass Jod, im Gegensatz zum Jodotbyrin, erregend auf das sympathische Nervensystem (Nn. accelerantes und Vasoconstrictoren) und deprimirend auf das hemmende Nervensystem (Vagi und Depressores) wirken ${ }^{1}$ ).

Auf diesen Gegensatz, sowie auf die in demselben Sinne sprechenden Beobachtungen an thyreodectomirten und an strumösen Thieren gründete v. Cy on auch vorzugsweise seine Theorie der Schilddrüsenwirkungen.

Sehen wir nun zu, wie in den Laudenbach' schen Versuchen die Einführungen von reinem Jod auf das Herz- und Gefässnervensystem wirken.

Versuch 1. Hund. Allmälige Einspritzungen (21 Mal) von 0,48 $\mathrm{g}$ Jod in einer Serumlösung; $1 \mathrm{ccm}$ Serum enthielt 1 oder $2 \mathrm{mg}$ Jod. Im Beginne des Versuches war der Blutdruck $129 \mathrm{~mm}$, die Zahl der Pulsschläge 12 in 10 Secunden. Untersuchen wir nun die Veränderungen des Blutdrucks und der Pulszahl während der 21 Einspritzungen, so finden wir folgende Steigerungen: Blutdruck 143, $180,170,184,200,220,180,190,120,150,220$. Zahl der Pulsschläge: 20, 22, 14, 27, 25, 28, 36. (Die letzte Zahl nach Durchschneidung des rechten Vagus.)

Wir sehen also, dass der Blutdruck mehrmals fast um das Doppelte, die Zahl der Pulsschläge fast um das Dreifachegestiegen waren.

A]so - vollste Uebereinstimmung mit den Angaben von v. C y on und mir. Man vergleiche nun diesen Versuch (nur Jod) z. B. mit dem v. Cy on vom 13. August. (Beiträge etc. s. S. 176, wo Jodnatrium gebraucht wurde.)

1) E. v. Cyon, Beitràge zur Physiologie der Schilddrüse und des Herzens. Dieses Arch. Bd. 70 S. 7. 
Versuch 2. Hund. Zur Einspritzung gelangten 1,755 g Jod in zwei Lösungen: die eine enthielt auf $1 \mathrm{ccm}$ Serum $3 \mathrm{mg}$ Jod (Jod und Jodnatrium); die zweite auf $1 \mathrm{ccm}$ Serum zwei mg Jod. Blutdruck vor jeder Einspritzung $71 \mathrm{~mm}$; Pulszahl 21 in 10 Secunden. Die Aenderung des Blutdrucks und der Schlagzahl waren während der 10 Einspritzungen $74 \mathrm{~mm}$ und 20 Pulsschläge, $85 \mathrm{~mm}$ und 20 Pulsschläge, $82 \mathrm{~mm}$ und 20 Pulsschläge, $82 \mathrm{~mm}$ und 19 Pulsschläge, $85 \mathrm{~mm}$ und 20 Pulsschläge, $104 \mathrm{~mm}$ und 20 Pulsschläge (r. Vagus durchschnitten), $183 \mathrm{~mm}$ und 31 Pulsschläge (l. Vagus durchschnitten), $132 \mathrm{~mm}$ und 22 Pulsschläge. Am Ende der zehnten Einspritzung von $12 \mathrm{mg}$ Jod Blutdruck $167 \mathrm{~mm}$ und Pulszahl 21.

Versuch 4. Hund. Einspritzung von $3,25 \mathrm{~g}$ Jod. Beide Vagi schon im Beginn des Versuches durchschnitten.

Blutdruck $131 \mathrm{~mm}$ und Pulszahl 37 in 10 Secunden. Trotz dieses schon sehr hohen Drucks und ungemein beschleunigten Pulsschlägen stieg noch der Druck bei den ersten Einspritzungen bis zu $183 \mathrm{~mm}$ und die Pulsschläge auf 41 in 10 Secunden. Bei den letzten Einspritzungen der ungeheuren Mengen von Jod $(3,25 \mathrm{~g})$ trat der Tod des Thieres bei niedrigem Druck ein.

Auch das Anhalten der Athmung vermochte nicht den Blutdruck in die Höhe zu bringen.

Der Versuch am Kaninchen soll noch ausgeführt werden:

Versuch 5. (1,21 k). Sämmtliche Herznerven am Halse durchtrennt. Blutdruck $55 \mathrm{~mm}$, Pulsschlag 31 in 10 Secunden. Nach den ersten Einspritzungen stieg der Druck auf $86 \mathrm{~mm}$ und 28 Pulsschläge, $104 \mathrm{~mm}$ und 21 Pulsschläge. Bei den weiteren Einspritzungen begann der Druck zu sinken; Tod des Thieres nach Einspritzung von im Ganzen $0,025 \mathrm{~g} \mathrm{~J}$.

Versuch 6. Alleinige Einspritzung von NaJ.

H und. Im Beginn des Versuchs Blutdruck $102 \mathrm{~mm}$ und 26 Pulsschläge in 10 Secunden. Bei der Einspritzung steigt der Druck bis zu $157 \mathrm{~mm}$ und die Zahl der Herzschläge auf 34. Analoge Resultate in den ähnlichen Versuchen VII und VIII an Hunden und im Versuche IX am Kaninchen. Mit einem Worte, in sämmtlichen von Laudenbach angeführten Versuchen (mit alleiniger Ausnahme des dritten, wo der Druck von Anfang an sehr niedrig war und das Thier schon im Beginn des Versuchs nach Einspritzung von bloss $0,75 \mathrm{~g}$ Jod verschied) erzeugte Einführung von reinem Jod oder von NaJ beträchtliche Steigungen des Blutdrucks und Be- 
schleunigungen des Pulses . . ganz entsprechend den Angaben von v. Cyon und von mir. Wo soll hier aber der Widerspruch bestehen?

Nur bei Einführung von einer so beträchtlichen Menge wie 3,25 g Jod sank der Blutdruck endlich: Das überreizte Gefässnervencentrum wurde durch die zu starke Dosis Jod gelähmt; wie dies zu der Wirkungslosigkeit der Athmungssuspension schon zur Genüge beweist.

Die Widerlegung meiner Schlussfolgerungen soll darin liegen, dass Laudenbach mehrmals in seinen Versuchen die Erregbarkeit der Vagi bei Einführung von reinem Jod unverändert fortbestehen, ja sogar mehrmals steigen sah. Blieb sie aber wirklich unverändert? Darüber lassen die Versuche von Laudenbach keinen sicheren Schluss zu.

In einigen Versuchen (z. B. in 1 und 2) war die Erregbarkeit vor den Einspritzungen nicht geprüft worden. Dagegen zeigen die ungeheuren Beschleunigungen, dass die Wirkung der Vagi abgenommen hat. In allen Versuchen gesehah die Prüfung der Erregbarkeit mit Hülfe eines ungraduirten Inductoriums; und, soweit man nach den ungenügenden Angaben beurtheilen kann, mit sehr intensiven Strömen. Nun handelt es sich, wie aus unseren Versuchen hervorgeht, meistens um geringe Schwankungen der Erregbarkeit, die ganz genauer Messungen erfordern, um erkannt zu werden. Bei der Einführung von Jod in Form von NaJ beim Kaninchen beobachtete auch Laudenbach ebenso wie ich eine bedeutende Herabsetzung der Erregbarkeit der Vagi. „Bei solchen Thieren genügt schon die Einführung der Hälfte der für's Herz tödtlichen Dosis, damit die Erregung der peripheren Enden der Vagi wirkungslos bleibt." (S. 38.)

"Der Depressor hat sich bei unserem Kaninchen," schreibt $\mathrm{L}$ a u d e n b a cb, „resistenter erwiesen als bei den Berner Kaninchen, an denen Barbèra gearbeitet hat .... (S. 25). Nun bei stärkeren Dosen von NaJ vermögen auch die stärksten Erregungen des Depressor nur ganz geringe Drucksenkungen zu veranlassen." Dies stimmt ja wieder ganz mit der von v. Cyon behaupteten Thatsache, dass die Depressoren bei strumösen Thieren viel weniger resistent sind.

Bei Hunden erhielt Laudenbach nach Reizung des centralen Endes des Vagus, die ja gewöhnlich Drucksenkungen erzeugt (wegen der im Vagusstrome verlaufenden Depressor-Fasern), ganz kolossale 
Drucksteigerungen nach Einführung von reinem Jod. So stieg im Versuche 1 der Blutdruck auf $244 \mathrm{~mm}$ und die Pulszahl auf 39 in $10 \ldots$..

Sollte Einführung von reinem Jod in den Versuchen von Laudenbach in der That die Erregbarkeit des Vagus nicht angegriffen haben, so könnte dies auch davon herrühren, dass die normalen Schilddrüssen bei seinen Hunden dieses Jod schnell unschädlich machten, wahrscheinlich durch Umwandlung in Jodothyrin. Dafür würden auch die Drucksenkungen sprechen, die häufig bei Hunden nach den grossen Drucksteigerungen folgten.

Mit einem Worte, die in Betracht kommenden thatsächlichen Ergebnisse der Laudenbach'schen Versuche bestätigen in glänzender Weise die Ergebnisse meiner Versuche. Berücksichtigt man, dass Laudenbach an nicht strumösen Thieren gearbeitet hat, während ich meistens mit strum ösen zu thun hatte, dass er an nicht narkotisirten Thieren arbeitete, während meine Versuchsthiere fast immer morphinisirt waren, endlich, dass er bei weitem stärkere Dosen Jod anwandte als ich, so muss diese Uebereinstimmung als besonders schätzbar betrachtet werden. Dass eine solche Uebereinstimmung für v. Cyon's Theorie der Schilddrüsenfunctionen nur erwünscht sein kann, ist selbstverständlich. Wie gesagt, sucht La udenbach die Ergebnisse der mit NaJ erhaltenen Versuche den Wirkungen von Na zuzuschreiben, wie dies schon $\mathrm{Harnack}^{1}$ ) gethan hat.

Dass dem nicht so sein kann, hat aber sehon v. Cy on in seiner Erwiderung dargethan ${ }^{2}$ ).

Die Erregbarkeitsabnahme des Depressor, welche auch L a u d enb a ch mehrmals beobachtet hat nach Einführungen von Jodnatrium, schliesst ja schon die Möglichkeit einer Abhängigkeit der hier in Betracht kommenden Wirkungen von einer Beeinflussung des Herzmuskels durch Natrium aus.

Uebrigens lassen die späteren Untersuchungen von v. Cy o n über die physiologischen Herzgifte, besonders die Versuche mit NaJ, Muscarin, Jodothyrin und Atropin, die L a u d e n b a ch noch unbekannt waren, erkennen, dass unsere Erklärung die allein richtige sein kann. Der von uns constatirte Antagonismus zwischen den Wirkungen des phosphorsauren Natrons und denen des Jodnatriums auf die Erregbar-

1) Centralblatt f. Physiologie Bd. 12.

2) Ebendaselbst. 
318 A. G. Barbèra: Der Einfluss von Jod, Jodnatrium und Jodothyrin etc.

keit der Vagi und Depressores beweist ja zur Evidenz, dass es bei den Anwendungen dieses letzten Präparates sich nicht um die Wirkungen des Natrons handeln kann. In der That vermochte das phosphorsaure Natron die unter dem Einflusse des Jodnatriums fast ganz erloschene Erregbarkeit der Vagi und Drepressores wieder herzustellen.

$\mathrm{L} a \mathrm{uden} \mathrm{ba} \mathrm{ch} \mathrm{ist} \mathrm{bei} \mathrm{seinen} \mathrm{Einwänden} \mathrm{gegen} \mathrm{unsere} \mathrm{Auffassung}$ der Jodwirkungen von der Voraussetzung geleitet worden, dieselbe stehe im Widerspruch mit den heilsamen Wirkungen des Jod bei gewissen strumösen Erkrankungen. Diese Voraussetzung beruht auf einem Missverständniss der C y on 'schen Theorie, die Functionen der Schilddrüsse betreffend. Es wird genügen, auf das Capitel 7 von dessen Beiträgen zur Physiologie der Schilddrüse sowie auf den ersten Theil der physiologischen Herzgifte zu verweisen, um sich davon zu überzeugen. Die Zufuhr von Jod ist erforderlich, um gewisse im Blute vorhandene toxische Zersetzungsproducte durch deren Verwandlung in Jodothyrin dem Organismus nutzbringend zu machen. Die Zufuhr zu grosser Mengen von Jod kann in gewissen Fällen ebenso schädigend wirken-wie der Mangel von Jod. „Bei meiner Definition der Schilddrüsenfunctionen", schreibt $\mathrm{Cy}_{0} \mathrm{n}^{1}$ ), „konnte die Entstehung des Kropfes ebenso gut dureh den Mangel an Jod im Trinkwasser wie durch dessen Ueberfluss begünstigt werden."

\section{Berichtigung. \\ Von}

Dr. Zaudy.

In dem von mir verfassten Theile der im 1 . Hefte dieses Bandes erschienenen Arbeit "Ueber die bei Vögeln künstlich zu erzeugenden Harnsäure-Ablagerungen" habe ich auf S. 83 Z. 9 v. u. von den Bilirubinkrystallen gesagt:

„Einzelne Krystalle sollen nach Letzterem (Orth) allerdings in der Niere Erwachsener ,im Leben' vorkommen."

Herr Geh. Rath $0 \mathrm{rth}$ hat mich inzwischen darauf aufmerksam gemacht, dass die betreffende Stelle seiner Arbeit (Virchow's Archiv Bd. 63 S. 458) sich nicht auf alle Gallenfarbstoffpartikel (krystallinische und amorphe), sondern nur auf die amorphen bezieht.

Es wird somit die ausschliesslich postmortale Entstehung der Bilirubinkrystalle im Körper noch wahrscheinlicher.

1) Beiträge etc. Dieses Arch. Bd. 70 S. 219. 